\title{
Venous thrombosis: not always in the legs
}

\author{
Muhammad Javaid Hameed Rahmani, Gitanjali Amaratunga, Oliver Wright
}

Conquest Hospital, St Leonards-on-Sea, UK

\section{Correspondence to}

Dr Muhammad Javaid Hameed Rahmani,

m.rahmani3@nhs.net

Accepted 21 November 2014

\section{DESCRIPTION}

We present a case of a 69-year-old woman who was initially admitted due to a fall and was treated for an infective exacerbation of chronic obstructive pulmonary disease (COPD), severe acute kidney injury and left femoral condyle fracture. These issues resolved and the fracture was managed conservatively. By then the patient had been a hospital inpatient for 3 weeks. She was stable, awaiting social services input and discharge planning.

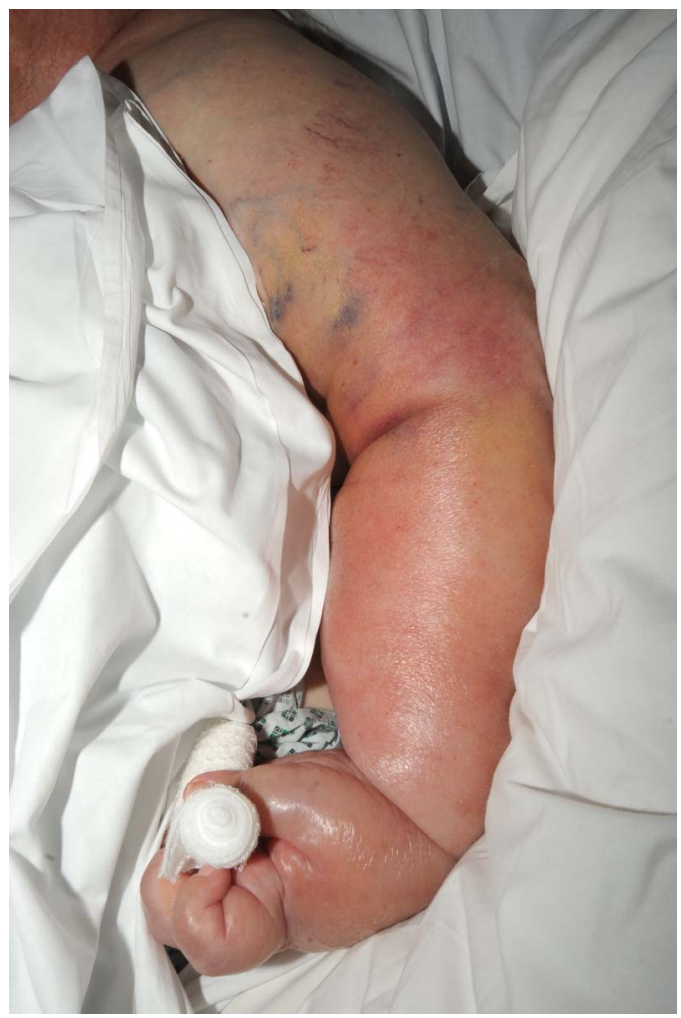

Figure 1 Redness, swelling and prominent superficial veins on the left arm.

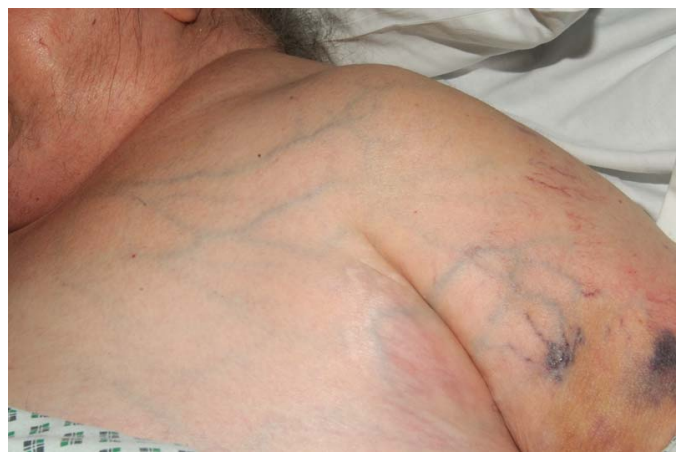

Figure 2 Prominent veins and thrombotic phlebitis of the superficial veins on the left upper arm and chest.

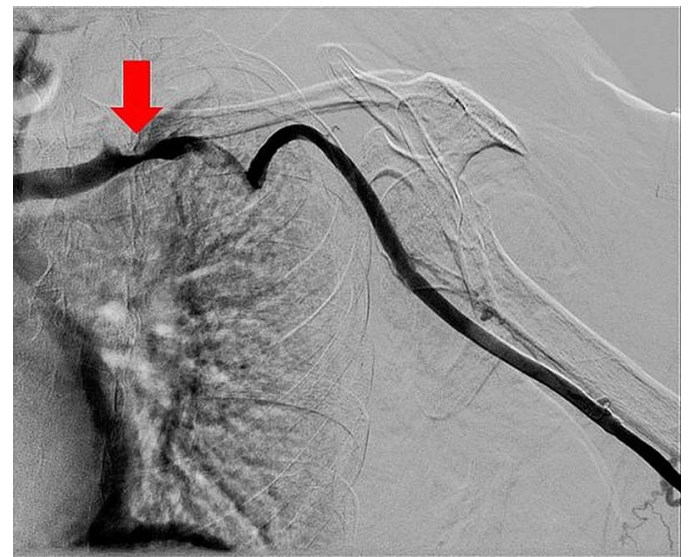

Figure 3 Left arm venogram demonstrating left subclavian thrombosis.

The patient had multiple comorbidities, including cognitive impairment. She had a medical history of COPD, bullous pemphigoid, anxiety and depression, and a cerebrovascular accident in 2010 with the residual effect of left arm weakness and

\section{Learning points}

- Venous thromboembolism (VTE) is a condition in which a blood clot (thrombus) forms in a vein. Most commonly occurring in the deep veins of the legs the thrombus may dislodge from its site of origin to travel in the blood-a phenomenon called embolism.

- The House of Commons Health Committee ${ }^{1}$ reported in 2005 that an estimated 25000 people in the UK die from preventable hospital-acquired VTE every year. Approximately $4-10 \%$ of all cases of venous thrombosis may involve the subclavian, axillary or brachial veins, ${ }^{2}$ and are associated with significant morbidity and mortality due to the potential risks of pulmonary embolism (PE). About $7-20 \%$ develop PE and $1 \%$ die. $^{3}$

- Venous thrombosis is a condition that should initially be diagnosed clinically. Prominent veins and thrombotic phlebitis of the superficial veins on the upper arm and chest should alert clinicians to the underlying venous thrombosis, prompting urgent investigations and treatment to prevent potentially fatal pulmonary thromboembolism.

- This case also demonstrates that clinicians are normally very wary of lower limb VTE but, although less common, they should also be aware and consider the possibility of upper limb thrombosis, particularly in very immobile patients with clinical signs. 
contracture. Her body mass index was $36 \mathrm{~kg} / \mathrm{m}^{2}$. Owing to a large body habitus, the residual effects of a previous ischaemic stroke and recent femoral condyle fracture, this patient was extremely immobile.

The medical team noticed that the patient's left arm had become increasingly swollen, erythematous and tender (figure 1). It was also noted that there were prominent veins and thrombotic phlebitis of superficial veins on her left upper arm and chest (figure 2). There was no lower limb deep venous thrombosis. The patient did not have a collagen disorder or Behçet's disease.

Despite being on prophylactic enoxaparin, the clinical picture was highly suspicious of upper arm vein thrombus and therefore the team started her on a treatment dose of enoxaparin and an ultrasound was requested. The ultrasound was inconclusive due to the patient's obesity, but a venogram clearly demonstrated a left subclavian vein thrombus (figure 3). The patient was started on rivaroxaban to prevent further thromboembolism.
Contributors GA was involved in case report and discussion and amalgamating learning points; OW in case discussion; and MJHR in formulating the idea for case report, identifying references for learning points.

Competing interests None.

Patient consent Obtained.

Provenance and peer review Not commissioned; externally peer reviewed.

\section{REFERENCES}

1 House of Commons Health Committee. The prevention of venous thromboembolism in hospitalised patients. London: The Stationery Office, 2005. http://www.nice.org.uk/ guidance/Cg92/chapter/Introduction

2 Spiezia L, Simioni P. Upper extremity deep vein thrombosis. Intern Emerg Med 2010;5:103-9.

3 Sajid MS, Ahmed N, Desai M, et al. Upper limb deep vein thrombosis: a literature review to streamline the protocol for management. Acta Haematol 2007; 118:10-18.

Copyright 2014 BMJ Publishing Group. All rights reserved. For permission to reuse any of this content visit

http://group.bmj.com/group/rights-licensing/permissions.

BMJ Case Report Fellows may re-use this article for personal use and teaching without any further permission.

Become a Fellow of BMJ Case Reports today and you can:

- Submit as many cases as you like

- Enjoy fast sympathetic peer review and rapid publication of accepted articles

- Access all the published articles

- Re-use any of the published material for personal use and teaching without further permission

For information on Institutional Fellowships contact consortiasales@bmjgroup.com

Visit casereports.bmj.com for more articles like this and to become a Fellow 